\title{
Study of the hearing in children born from pregnant women exposed to occupational noise: Assessment by distortion product otoacoustic emissions
} Eduardo Bezerra Rocha ${ }^{1}$, Marisa Frasson de
Azevedo ${ }^{2}$, João Aragão Ximenes Filbo
Keywords: hearing, occupational/prevention, control, noise.

\section{Summary}

\begin{abstract}
A
To detect early on a probable hearing loss in children of women exposed to occupational noise during their pregnancy and to verify if there is any difference between the children from those women exposed to occupational noise during their pregnancy and the ones from mothers that do not work under the same conditions. Methods: Children from women exposed to occupational noise during their pregnancy and children from women who were not exposed were evaluated through distortion product otoacoustic emissions, using the GSI 60 DPOEA SYSTEM equipment and the frequency-ratio $\mathrm{F}_{2} / \mathrm{F}_{1}$ equal to 1.2 and the geometric average of $2 \mathrm{~F}_{1}-\mathrm{F}_{2}$. The intensity of the primary frequencies were kept steady with values of $\mathrm{L} 1=65 \mathrm{dBSPL}$ and $\mathrm{L} 2=55 \mathrm{dBSPL}$ for $F_{1}$ and $F_{2}$, respectively. Student $T$ test in paired samples and independent samples were used. Results: There were no differences in the response amplitude of distortion product otoacoustic emissions between the control and the study groups. There was no statistically difference between male and female children in response amplitude for the two groups aforementioned; and there were no differences between right and left ears from each group. Conclusion: We did not observe hearing impairment in children whose mothers were exposed to occupational noise during pregnancy when compared to the children from mothers who were not. There was no difference between the right and left ears, nor between male and female children in each group.
\end{abstract}

${ }^{1}$ MD. Otorhinolaryngologist - SBORL; M.S in Human Communication - UNIFESP-EPM/ UNIFOR. Professor. 


\section{INTRODUCTION}

Although temporary, sound pollution is responsible for great harm. Such pollution, dealt upon as noise, can be social or occupational. Social noise is the one caused by discos, noisy cars, rock bands, usually of short duration and that, if isolated and episodic, would hardly cause hearing problems to men ${ }^{1}$.

In general, those who work exposed to noise levels above $85 \mathrm{dBSPL}$ and under long standing exposure must be monitored. Auditory monitoring can be carried out by means of threshold tonal audiometry, which determines the least sound intensity capable of causing auditory sensation in each frequency tested, using a pure sound stimulus, and this is the one most employed in factories.

Another method is evoked otoacoustic emmission29 which is obtained in response to previous sound stimulation, and it can be with pure tones - by distortion products of pre-established frequencies, which analyzes cochlear activities in specific frequencies ${ }^{10-13}$ or by a very short sound stimulus, a "click" - transitory and that represent a global cochlear response ${ }^{11}$. It is an objective, quick, non-invasive and easily applicable method ${ }^{14-17}$, including the screening of children in high risk nurseries ${ }^{18}$.

Until very recently, the concern in assessing the hearing of those exposed to noise was limited to males. However, with the need to contribute financially to the household, women today represent almost $50 \%$ of the work force and are present in a sizeable share of the world industrial setting and, most of them are in their reproductive years ${ }^{19}$. It is known that there is a greater individual susceptibility; however, there is no clinical evidence that men or women be more prone to hearing problems when exposed to noise.

It is known that when a sound wave goes from the air medium (outer and middle ear) to the liquid medium (labyrinthine liquids), $99.9 \%$ of this energy is lost. It is also known that the human fetus is protected inside the mother's womb and the tissues and liquid around this harmless being may damp environmental noise ${ }^{20,21}$ and, according to a quote from Niemtzow ${ }^{22}$ (1982), such damping shall be more effective as the frequency increases. Thus, lower frequencies are less damped, and therefore are the most harmful to the fetal cochlea.

Many are the papers that discuss the effects of occupational noise on the fetus ${ }^{21-26}$; however, few approach its effects on the fetus's hearing27. It is debated whether or not noise may cause low birth weight ${ }^{28,29}$ or bring about alterations to the immune system30. The possible devastating effect occupational noise may have on this future human has been considered, and thus we deemed relevant to invest in this research project, trying to establish a cause/effect relation in regards of these women and their work environment.
In the present investigation, the target public is, therefore, the children born from women who, during pregnancy were exposed to occupational noise. Since tonal audiometry is a method that is impossible to be used in neonates because it requires a behavioral answer from the examinee, otoacoustic emissions bear the ideal traits to be the exam of choice in these cases ${ }^{3,12}$.

The goals of the present investigation were:

1. Provide for an early detection of hearing loss in children born from women exposed to occupational noise during pregnancy;

2. Check to see whether there is any difference in the results of otoacoustic emissions - distortion product - amplitudes among the children born from mothers who were exposed to occupational noise and the children born from mothers who were not exposed to occupational noise.

\section{PATIENTS AND METHODS}

\section{Patients}

This work was developed at the department of Speech and Hearing Therapy of the Núcleo de Atenção Médica Integrada (NAMI), of the University of Fortaleza (UNIFOR), from August 2002 through June of 2003. Patients underwent otorhinolaryngology exam, followed by otoacoustic emissions - distortion product (DPOAM), after informing the guardian and obtaining a signed consent. The study was approved by the Ethics Committee of both universities: University of Fortaleza and the Federal University of São Paulo (UNIFESP-EPM), protocol \# 0330/03.

The object of our study were children with ages ranging from 0 to 6 months, of both genders and without any risk factor for hearing loss, according to the recommendations established by the preliminary screening group of neonatal screening, formed by the Brazilian Society of Otorhinolaryngology in May of 2000. Those children who presented some risk indicator for hearing loss were taken off the study.

The women (mothers) come from the same socioeconomical background (family income equivalent to 1-2 minimum wages). We also excluded those women who worked exposed to chemical products and who smoked during pregnancy ${ }^{26}$.

Questionnaires were answered during interview with the researcher on the pregnancy and delivery conditions, considering birth weight and height, mother's and relatives' past, and that of the child being investigated, and also the mother's professional activity during pregnancy. Thus, all the aforementioned variables were eliminated and the children were selected.

All the children were submitted to an otorhinolaryngological evaluation, in an attempt to investigate cranio-facial malformations and rule out external and/or 
middle ear involvement, by means of an otoscopy. Those children with external and/or middle ear problems were treated clinically and then reassessed. When there were within normal parameters, they were approved to join the study.

The study was carried out with 80 children who were distributed in two groups: study and control. The first was made up of 35 children with ages varying between 0 and 6 months, of both genders, born from women exposed to occupational noise above 80dBSPL (intensity range above 80dBSPL and below 90dBSPL), in an 8 hour daily work routine, making up a total of 40 hours per week of work during pregnancy, and whom both the gestation and delivery happened without complications. The children hereby studied are from women who worked in a nuts processing plant, located in the city of Cascavel, in the state of Ceará, $60 \mathrm{Km}$ away from Fortaleza. All these women worn personal protection equipment (PPE) - ear plug - during their work routine and kept working exposed to occupational noise until at least the 8th month of pregnancy, and most took maternity leave 15 days before delivery (Table 1).

The control group was formed by 45 children, also from both genders, with matching ages to those in the study, born from women who were not exposed to occupational noise during gestation, from the Dendê community and who are followed at the NAMI, without the same hearing loss risk factors of those children in the study, who went through the same assessment procedure (Table 1).

Table 1. Children distribution by gender and group.

\begin{tabular}{cccc}
\hline & Males & Females & Total \\
\hline Control Group. & $26(57.7 \%)$ & $19(42.3 \%)$ & 45 \\
Study Group. & $16(45.7 \%)$ & $19(54.3 \%)$ & 35
\end{tabular}

\section{Method}

All women in both groups received prenatal care and conceived children in public maternities under the care of a health care professional. Data on birth conditions and the child's status at delivery were collected from the child's vaccination card or from the birth records provided by the maternity.

\section{Otoscopic Exam}

The equipment used for the otorhinolaryngological assessment were a Kole headlamp and a Heine otoscope. This assessment was necessary in order to check external and middle ear integrity, which function is essential in order to properly capture the otoacoustic emissions.

\section{Distortion Product - Evoked Otoacoustic Emissions}

The children who passed the otorhinolaryngological exam were submitted to auditory analysis by means of the distortion product - evoked otoacoustic emissions.

In order to record the DPOAE we used a GSI 60 DPOEA SYSTEM. Recording took place after the generation of two pure tones F1 and F2, where F2 was always higher than F1 and were called primary frequencies. F2 varied between $593 \mathrm{~Hz}$ and $6031 \mathrm{~Hz}$ and its geometric average (GA) followed the 2F1-F2 standard in the F2/F1 ratio equal to 1.2. The primaries F1 and F2 (L1 for F1 and L2 for F2) stimuli intensities remained fixed at 65dBSPL and $55 \mathrm{dBSPL}$, respectively, in other words, L1 was greater than L2 in 10dBSPL. The DPOAE measures were carried out from the low to the high frequencies.

An acoustic probe with two receivers (micro-speakers) was coupled to the measuring device, which were responsible for the emission of acoustic signals (F1 and F2) and 1 high sensitivity miniature microphone used to collect the DPOAE, and this whole set of transducers were assembled in a small probe similar to the one used in immitanciometry, and which was coupled to the external auditory meatus by means of a rubber plug of proper size for each child tested.

The device was calibrated whenever turned on, using a $2 \mathrm{~cm}^{3}$ cavity simulator, where we checked the correct sealing and working of the transducers and necessary adjustments for calibration purposes were made by the device itself.

The distortion products and background noises were recorded and analyzed in relation to the sound frequencies, as shown on Table 2.

Table $2-F_{1}$ and $F_{2}$ primary frequencies and distortion product for 2 $\mathrm{F}_{1}-\mathrm{F}_{2}$

\begin{tabular}{|c|c|c|c|c|c|}
\hline \multicolumn{6}{|c|}{ Primary } \\
\hline Point & $\mathrm{F}_{1}$ & $\mathrm{~F}_{2}$ & $\mathrm{~F}_{2} / \mathrm{F}_{1}$ & $\mathrm{GM}(\mathrm{Hz})$ & $\mathrm{DP} 2 \mathrm{~F}_{1}-\mathrm{F}_{2}(\mathrm{~Hz})$ \\
\hline 1 & 500 & 593 & 1,2 & 531 & 406 \\
\hline 2 & 625 & 750 & 1,2 & 687 & 500 \\
\hline 3 & 781 & 937 & 1,2 & 843 & 625 \\
\hline 4 & 1000 & 1187 & 1,2 & 1093 & 812 \\
\hline 5 & 1250 & 1500 & 1,2 & 1375 & 1000 \\
\hline 6 & 1593 & 1906 & 1,2 & 1750 & 1281 \\
\hline 7 & 2000 & 2406 & 1,2 & 2187 & 1593 \\
\hline 8 & 2531 & 3031 & 1,2 & 2781 & 2031 \\
\hline 9 & 3187 & 3812 & 1,2 & 3500 & 2562 \\
\hline 10 & 4000 & 4812 & 1,2 & 4375 & 3187 \\
\hline 11 & 5031 & 6031 & 1,2 & 5500 & 4031 \\
\hline
\end{tabular}


DPOAE were considered present whenever the distortion product amplitude value were positive, with a difference equal to, or higher than 6dBSPL in relation to the background noise, in other words, a signal to noise ration difference equal to or higher than 6dBSPL. Negative amplitudes, with differences below 6dBSPL were considered absent. We always tried to keep noise levels below zero (negative). Cases of excessive noise, masking the response, were not analyzed.

The exam was carried out in an acoustically treated room and booth, in the selected children that, after fed, were sleepy or slightly asleep and in the arms of the mother or guardian.

\section{Statistical analysis}

The statistics used for data analysis was based on the t-Student test for averages comparison in: (i) paired samples (dependent) and (ii) independent samples.

The significance level used in the tests conclusion was of 0.05 in all the tables and we present edthe descriptive level of the tests (p-value), in other words, minimum significance level to be used for ruling out the hypothesis HO. Data were analyzed by means of the SPSS version 8.0 statistics software.

\section{RESULTS}

Study of the distortion product amplitudes and background noise in function of the ear side variable in both the control and the study groups

Hereby we present the results from the distortion product - evoked otoacoustic emissions and back ground noise in children born from mothers who were not exposed to occupational noise during pregnancy (control group), analyzing their response amplitudes for each ear and, following that, comparing them among each other. We used the t-Student test for paired samples (significant for $\mathrm{p}<0.05$ ) and there was no statistically significant difference between right and left ears for the distortion product and background noise amplitude averages in the control group. As for the study group, the right ear presented a statistically significant difference in the frequency of 1500 $\mathrm{Hz}$ when compared to the left ear, in other words, the right ear presented better distortion product amplitude average when compared to the left ear. As for background noise, there was no statistically significant difference between right and left ears in the study group.

Study of the distortion product amplitudes and background noise in function of the gender variable in both the control and the study groups

We analyzed the average with standard deviation measures for distortion product - evoked otoacoustic emissions and background noise in relation to gender for each group (study and control).

Boys presented better distortion product average amplitudes when compared to girls in the $\mathrm{F} 2$ frequencies of $1187 \mathrm{KHz}$ and $1500 \mathrm{KHz}$ for the control group, while girls had better distortion product amplitude averages when compared to boys in the F2 frequency of $2406 \mathrm{KHz}$. There was no statistically significant difference for background noise insofar as gender is concerned for both groups.

Comparative study of background noise and distortion product amplitudes between the control and study groups

Considering both ears together for the assessed group. There was no statistically significant difference between the two groups in relation to the averages of response amplitudes in distortion product. Both for the control and the study groups, background noise presented positive values for the low frequencies and negative values

Table 3 - mean values, standard deviation and student $t$ test (paired samples) in order to compare DP (distortion product) mean values obtained for right and left ears - control group

\begin{tabular}{|c|c|c|c|c|c|c|c|}
\hline \multirow{2}{*}{$\mathrm{F} 2 \mathrm{~Hz}$} & \multicolumn{2}{|c|}{ Right Ear } & \multicolumn{2}{|c|}{ Left Ear } & \multirow{2}{*}{$\mathrm{t}$} & \multirow{2}{*}{ gl } & \multirow{2}{*}{$p$-value } \\
\hline & DP Mean value & Standard Deviation & DP Mean value & Standard Deviation & & & \\
\hline 593 & 9,24 & 7,69 & 12,16 & 8,73 & $-1,617$ & 44 & 113 \\
\hline 750 & 3,51 & 7,01 & 5,33 & 9,18 & $-1,178$ & 44 & ,245 \\
\hline 937 & 6,82 & 6,19 & 7,49 & 6,98 & $-0,645$ & 44 &, 523 \\
\hline 1187 & 10,73 & 6,39 & 9,62 & 7,06 & 1,189 & 44 & ,241 \\
\hline 1500 & 12,60 & 7,94 & 12,93 & 6,81 &,- 321 & 44 & ,750 \\
\hline 1906 & 15,62 & 7,09 & 14,73 & 6,52 & 1,019 & 44 & ,314 \\
\hline 2406 & 14,51 & 5,20 & 14,44 & 5,46 & 083 & 44 & 934 \\
\hline 3031 & 10,49 & 4,75 & 9,98 & 4,92 & ,737 & 44 & 465 \\
\hline 3812 & 10,93 & 5,78 & 9,98 & 5,30 & 1,144 & 44 & 259 \\
\hline 4812 & 8,20 & 5,96 & 6,47 & 5,70 & 1,779 & 44 & ,082 \\
\hline 6031 & 4,58 & 4,21 & 3,20 & 4,99 & 1,881 & 44 & ,067 \\
\hline
\end{tabular}


Table 4 - mean values, standard deviation and student $t$ test (paired samples) in order to compare BN (background noise) mean values obtained for right and left ears - control group

\begin{tabular}{|c|c|c|c|c|c|c|c|}
\hline \multirow{2}{*}{$\mathrm{F} 2 \mathrm{~Hz}$} & \multicolumn{2}{|c|}{ Right Ear } & \multicolumn{2}{|c|}{ Left Ear } & \multirow{2}{*}{$\mathrm{t}$} & \multirow{2}{*}{$\mathrm{gl}$} & \multirow{2}{*}{$p$-value } \\
\hline & Mean BN & Standard Deviation & Mean BN & Standard Deviation & & & \\
\hline 593 & 8,78 & 8,36 & 10,80 & 7,18 & ,618 & 44 &, 540 \\
\hline 937 & 0,89 & 4,87 & 2,07 & 5,41 & $-1,350$ & 44 & , 184 \\
\hline 1187 & $-0,20$ & 4,86 & 0,80 & 5,85 & ,369 & 44 & ,714 \\
\hline 1906 & $-5,73$ & 4,01 & $-4,31$ & 4,13 &,- 890 & 44 & ,378 \\
\hline 2406 & $-8,16$ & 2,77 & $-7,44$ & 3,66 & $-1,172$ & 44 & ,248 \\
\hline 3031 & $-9,82$ & 4,26 & $-8,84$ & 3,58 & $-1,510$ & 44 & ,138 \\
\hline 3812 & $-9,73$ & 3,36 & $-9,09$ & 2,87 &,- 961 & 44 & ,342 \\
\hline 4812 & $-8,27$ & 2,78 & $-8,60$ & 2,13 & $-1,211$ & 44 & ,232 \\
\hline
\end{tabular}

Table 5 - mean values and standard deviation of the distortion product difference with the background noise $(a=D P-B N)$ obtained for the right and left ears - control group

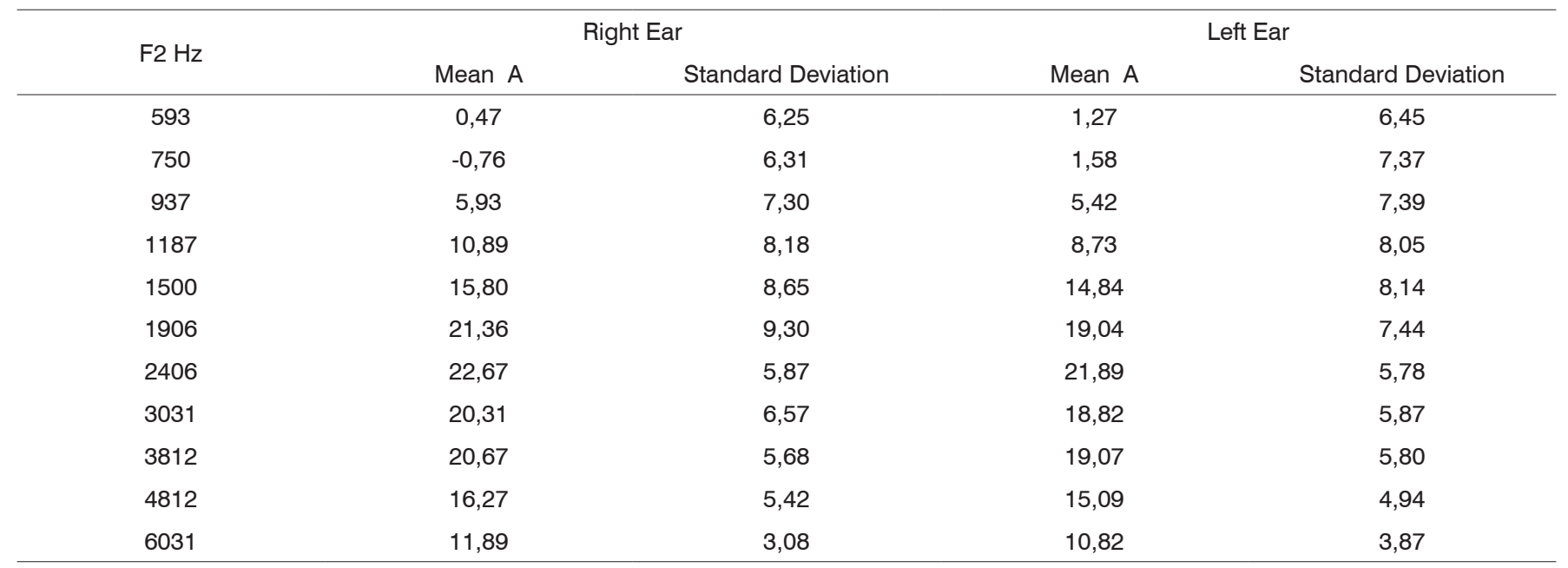

Table 6 - mean values, standard deviation and student t test (paired samples) in order to compare DP (distortion product) mean values obtained for right and left ears - study group

\begin{tabular}{|c|c|c|c|c|c|c|c|}
\hline \multirow{2}{*}{$\mathrm{F} 2 \mathrm{~Hz}$} & \multicolumn{2}{|c|}{ Right Ear } & \multicolumn{2}{|c|}{ Left Ear } & \multirow{2}{*}{$\mathrm{t}$} & \multirow{2}{*}{ gl } & \multirow{2}{*}{ p-value } \\
\hline & Mean value DP & Standard Deviation & Mean value DP & Standard Deviation & & & \\
\hline 593 & 9,46 & 11,10 & 11,71 & 8,31 &,- 966 & 34 & ,341 \\
\hline 937 & 7,80 & 6,41 & 7,51 & 6,36 & ,210 & 34 & ,835 \\
\hline 1187 & 10,51 & 5,52 & 8,37 & 7,73 & 1,653 & 34 & ,108 \\
\hline 1906 & 15,34 & 5,78 & 14,09 & 6,99 & 1,204 & 34 & ,237 \\
\hline 2406 & 15,49 & 6,34 & 14,34 & 5,70 & 1,145 & 34 & ,260 \\
\hline 3031 & 10,46 & 4,84 & 9,23 & 4,53 & 1,577 & 34 & ,124 \\
\hline 3812 & 10,77 & 5,92 & 10,34 & 4,29 & ,415 & 34 & ,680 \\
\hline 4812 & 8,49 & 5,87 & 7,31 & 4,23 & 1,039 & 34 & ,306 \\
\hline
\end{tabular}

Note: $\left(^{*}\right)$ Significant at $5 \%$ 
Table 7 - mean values, standard deviation and student $t$ test (paired samples) in order to compare BN (background noise) mean values obtained for right and left ears - study group

\begin{tabular}{|c|c|c|c|c|c|c|c|}
\hline \multirow{2}{*}{$\mathrm{F} 2 \mathrm{~Hz}$} & \multicolumn{2}{|c|}{ Right Ear } & \multicolumn{2}{|c|}{ Left Ear } & \multirow{2}{*}{$\mathrm{t}$} & \multirow{2}{*}{$\mathrm{gl}$} & \multirow{2}{*}{$p$-value } \\
\hline & Mean value DP & Standard Deviation & Mean value DP & Standard Deviation & & & \\
\hline 593 & 8,03 & 8,77 & 8,57 & 8,85 &,- 313 & 34 & ,756 \\
\hline 750 & 1,74 & 8,06 & 1,66 & 7,14 & ,072 & 34 & ,943 \\
\hline 937 & 0,17 & 6,37 & 0,51 & 4,87 &,- 311 & 34 & ,757 \\
\hline 1187 & $-2,23$ & 4,83 & $-2,40$ & 5,76 & , 157 & 34 & ,876 \\
\hline 1500 & $-3,09$ & 5,17 & $-3,06$ & 5,54 &,- 036 & 34 & ,971 \\
\hline 1906 & $-5,26$ & 4,41 & $-5,31$ & 4,51 & ,061 & 34 & ,952 \\
\hline 2406 & $-7,83$ & 3,23 & $-8,11$ & 3,25 & ,372 & 34 & ,712 \\
\hline 3031 & $-10,23$ & 4,02 & $-9,20$ & 3,25 & $-1,298$ & 34 & 203 \\
\hline 3812 & $-9,14$ & 2,98 & $-9,31$ & 3,26 & ,214 & 34 & ,832 \\
\hline 4812 & $-8,63$ & 3,12 & $-8,26$ & 2,21 &,- 549 & 34 &, 586 \\
\hline 6031 & $-7,34$ & 2,03 & $-8,14$ & 3,24 & 1,360 & 34 & 183, \\
\hline
\end{tabular}

Table 8 - mean values and standard deviation of the distortion product difference with the background noise $(a=D P-B N)$ obtained for the right and left ears - study group

\begin{tabular}{ccccc}
\hline F2 Hz & \multicolumn{2}{c}{ Right Ear } & \multicolumn{2}{c}{ Left Ear } \\
& Mean A & Standard Deviation & Mean A & Standard Deviation \\
\hline 750 & 3,26 & 7,32 & 2,66 & 7,62 \\
937 & 7,63 & 7,38 & 7,00 & 7,19 \\
1187 & 12,74 & 6,73 & 10,77 & 9,48 \\
1500 & 18,11 & 7,34 & 15,94 & 8,11 \\
1906 & 20,60 & 7,92 & 19,66 & 6,23 \\
2406 & 23,31 & 6,90 & 22,23 & 6,86 \\
3031 & 20,74 & 6,74 & 18,43 & 5,94 \\
3812 & 19,91 & 5,56 & 19,66 & 4,99 \\
4812 & 17,11 & 5,36 & 15,57 & 4,14 \\
6031 & 12,23 & 4,99 & 10,94 & 4,49 \\
\hline
\end{tabular}

Table 9 - mean values, standard deviation and student t test (independent samples) in order to compare DP (distortion product) mean values assessed by gender - control group

\begin{tabular}{|c|c|c|c|c|c|c|}
\hline \multirow{2}{*}{$\mathrm{F} 2 \mathrm{~Hz}$} & \multicolumn{2}{|c|}{ Male } & \multicolumn{2}{|c|}{ Female } & \multirow{2}{*}{$p$-value ${ }^{1} \mathrm{~F}$} & \multirow{2}{*}{$p$-value ${ }^{2} t$} \\
\hline & Mean value DP & Standard Deviation & Mean value DP & Standard Deviation & & \\
\hline 593 & 9,7692 & 7,7576 & 11,9737 & 8,9608 &, 582 & ,216 \\
\hline 937 & 7,5192 & 6,5334 & 6,6579 & 6,6790 & ,915 & ,542 \\
\hline 1187 & 11,4423 & 6,1911 & 8,4474 & 7,0966 & ,743 & ,036 $\left(^{\star}\right)$ \\
\hline 1906 & 16,0000 & 6,2151 & 14,0526 & 7,4360 &, 117 & , 180 \\
\hline 2406 & 14,5962 & 4,6579 & 14,3158 & 6,1385 & ,088 & ,806 \\
\hline 3031 & 10,0192 & 4,0752 & 10,5263 & 5,7127 & ,075 & ,624 \\
\hline 3812 & 9,9231 & 5,0014 & 11,1842 & 6,1857 & ,138 & ,288 \\
\hline 4812 & 6,9423 & 5,5850 & 7,8684 & 6,2522 & ,333 & ,462 \\
\hline
\end{tabular}

Note: (1) Levene test for equality of variances, (2) t-Student test for independent samples. 
Table 10 - mean values, standard deviation and t-student test (independent samples) in order to compare BN assessed by gender - control group

\begin{tabular}{|c|c|c|c|c|c|c|}
\hline \multirow{2}{*}{$\mathrm{F} 2 \mathrm{~Hz}$} & \multicolumn{2}{|c|}{ Male } & \multicolumn{2}{|c|}{ Female } & \multirow{2}{*}{$p$-value ${ }^{1} \mathrm{~F}$} & \multirow{2}{*}{$\mathrm{p}$-value ${ }^{2} \mathrm{t}$} \\
\hline & Mean value $B N$ & Standard Deviation & Mean value $B N$ & Standard Deviation & & \\
\hline 593 & 9,3846 & 7,0909 & 10,3421 & 8,7774 & ,021 & ,582 \\
\hline 750 & 4,0962 & 7,3518 & 3,8947 & 7,1236 & ,886 & ,897 \\
\hline 937 & 1,9231 & 4,7023 & 0,8684 & 5,7147 & ,096 & ,340 \\
\hline 1187 & 0,1346 & 5,7804 & 0,5263 & 4,8253 & ,367 & ,735 \\
\hline 1500 & $-2,1923$ & 5,7770 & $-3,0526$ & 5,1933 & ,742 & ,469 \\
\hline 1906 & $-4,9038$ & 4,4336 & $-5,1842$ & 3,6676 & ,289 &, 751 \\
\hline 2406 & $-8,0769$ & 2,9362 & $-7,4211$ & 3,6364 & 981 & ,347 \\
\hline 3031 & $-9,0577$ & 3,8573 & $-9,7105$ & 4,0797 & ,775 & ,441 \\
\hline 3812 & $-8,9231$ & 2,8343 & $-10,0789$ & 3,4041 & ,114 & ,083 \\
\hline 4812 & $-8,5385$ & 2,3218 & $-8,2895$ & 2,6803 & ,235 & ,639 \\
\hline 6031 & $-7,7308$ & 2,4344 & $-7,1053$ & 1,6240 & ,008 & 148 \\
\hline
\end{tabular}

Note: (1) Levene test for equality of variances, (2) t-Student test for independent samples

Table 11 - mean values, standard deviation and t-student test (independent samples) in order to compare DP mean values assessed by gender - study group

\begin{tabular}{|c|c|c|c|c|c|c|}
\hline \multirow{2}{*}{$\mathrm{F} 2 \mathrm{~Hz}$} & \multicolumn{2}{|c|}{ Male } & \multicolumn{2}{|c|}{ Female } & \multirow{2}{*}{$p$-value ${ }^{1} \mathrm{~F}$} & \multirow{2}{*}{$p$-value ${ }^{2} t$} \\
\hline & Mean value DP & Standard Deviation & Mean value DP & Standard Deviation & & \\
\hline 593 & 11,6563 & 10,5788 & 9,6842 & 9,1359 & ,244 & ,406 \\
\hline 937 & 7,6875 & 5,0189 & 7,6316 & 7,3427 &, 037 & 971 \\
\hline 1187 & 9,6875 & 7,5024 & 9,2368 & 6,1444 &, 549 & ,783 \\
\hline 1906 & 13,7500 & 6,7633 & 15,5263 & 6,0437 & ,171 & ,250 \\
\hline 2406 & 13,2813 & 6,1184 & 16,2895 & 5,6325 & ,862 &, $036(*)$ \\
\hline 3031 & 9,0313 & 4,2539 & 10,5263 & 4,9850 & ,267 & 186 \\
\hline 3812 & 10,4688 & 4,1034 & 10,6316 & 5,9248 & 232 & ,896 \\
\hline 4812 & 7,2813 & 4,6851 & 8,4211 & 5,4556 & ,410 & ,357 \\
\hline
\end{tabular}

Note: (1) Levene test for equality of variances, (2) t-Student test for independent samples, $\quad{ }^{\star}$ ) Significant at $5 \%$

for the (F2) frequencies starting at $1500 \mathrm{~Hz}$ for the control group and at $1187 \mathrm{~Hz}$ for the study group.

\section{DISCUSSION}

The choice for distortion product - evoked otoacoustic emissions was based on their wide clinical application:

1) in assessing the cochlear external hair cells function ${ }^{11}$;

2) it is frequency-specific;

3) recommended for use in babies and

4) are able to detect changes in auditory threshold even before conventional tonal audiometry does 9
In order to obtain a better response amplitude and less background noise interference, distortion productevoked otoacoustic emissions were applied to the population studied, following the criteria: F2/F1 equal to 1.2, geometric average of the $\mathrm{F} 1$ and $\mathrm{F} 2$ primary frequencies in 2F1-F2; and the stimuli intensities of F1 and F2 were of 65 $\mathrm{dB}$ SPL and $55 \mathrm{~dB}$ SPL (that is: $\mathrm{L} 1=\mathrm{L} 2-10$ ), respectively ${ }^{4}$.

The distortion products-response-amplitude for both the right and left ears in the control group varied according to frequency F2, always presenting positive values in all the frequencies tested, the highest values were seen in the frequencies of $1500 \mathrm{~Hz}, 1906 \mathrm{~Hz}, 2406$ $\mathrm{Hz}, 3031 \mathrm{~Hz}$ and $3812 \mathrm{~Hz}$ for both ears. The highest peak 
Table 12 - mean values, standard deviation and t-student test (independent samples) in order to compare BN mean values assessed by gender - study group

\begin{tabular}{|c|c|c|c|c|c|c|}
\hline \multirow{2}{*}{$\mathrm{F} 2 \mathrm{~Hz}$} & \multicolumn{2}{|c|}{ Male } & \multicolumn{2}{|c|}{ Female } & \multirow{2}{*}{$p$-value ${ }^{1} F$} & \multirow{2}{*}{$p$-value ${ }^{2} t$} \\
\hline & Mean value DP & Standard Deviation & Mean value DP & Standard Deviation & & \\
\hline 593 & 10,1875 & 8,0380 & 6,7105 & 9,1087 & 177 & ,098 \\
\hline 750 & 3,4688 & 6,5401 & 2105 & 8,1046 & ,241 & ,072 \\
\hline 937 & 1,2188 & 5,0910 &,- 3947 & 6,0159 & , 154 & ,235 \\
\hline 1187 & $-2,2188$ & 5,1852 & $-2,3947$ & 5,4204 & ,918 & ,891 \\
\hline 1500 & $-3,4688$ & 4,9186 & $-2,7368$ & 5,6792 & ,392 &, 570 \\
\hline 1906 & $-5,9063$ & 3,9132 & $-4,7632$ & 4,8123 & ,115 & ,285 \\
\hline 2406 & $-7,7813$ & 2,5870 & $-8,1316$ & 3,6993 & ,151 & ,654 \\
\hline 3031 & $-9,2188$ & 3,3672 & $-10,1316$ & 3,8985 & ,247 & ,303 \\
\hline 3812 & $-9,0625$ & 2,9175 & $-9,3684$ & 3,2832 &, 581 & ,684 \\
\hline 4812 & $-8,3750$ & 2,4330 & $-8,5000$ & 2,9201 & ,961 & ,848 \\
\hline 6031 & $-7,5625$ & 2,9614 & $-7,8947$ & 2,5126 &, 525 & ,613 \\
\hline
\end{tabular}

Note: (1) Levene test for variances analyses, (2) t-Student test for independent samples.

Table 13 - mean values, standard deviation and t-student test (independent samples) in order to compare DP mean values between the control and study groups

\begin{tabular}{|c|c|c|c|c|c|c|}
\hline \multirow{2}{*}{$\mathrm{F} 2 \mathrm{~Hz}$} & \multicolumn{2}{|c|}{ Control } & \multicolumn{2}{|c|}{ Study } & \multirow{2}{*}{$p$-value ${ }^{1} F$} & \multirow{2}{*}{$\mathrm{p}$-value ${ }^{2} \mathrm{t}$} \\
\hline & Mean value DP & Standard Deviation & Mean value DP & Standard Deviation & & \\
\hline 593 & 10,7000 & 8,3106 & 10,5857 & 9,7987 & ,285 & ,937 \\
\hline 937 & 7,1556 & 6,5718 & 7,6571 & 6,3426 & ,360 & ,627 \\
\hline 1187 & 10,1778 & 6,7167 & 9,4429 & 6,7516 & ,931 & ,494 \\
\hline 2406 & 14,4778 & 5,3026 & 14,9143 & 6,0090 & ,397 & ,627 \\
\hline 3031 & 10,2333 & 4,8112 & 9,8429 & 4,6924 & ,653 & ,607 \\
\hline 3812 & 10,4556 & 5,5347 & 10,5571 & 5,1376 &, 584 & ,906 \\
\hline 4812 & 7,3333 & 5,8598 & 7,9000 & 5,1136 & 192 &, 522 \\
\hline
\end{tabular}

Note: (1) Levene test for equality of variances,(2) t-Student test for independent samples.

of response amplitude was seen at $1906 \mathrm{~Hz}$ and $2406 \mathrm{~Hz}$, with values of $15.62 \mathrm{dBSPL}$ and $14.51 \mathrm{dBSPL}$ for the right ear, and values of $14.73 \mathrm{dBSPL}$ and $14.44 \mathrm{dBSPL}$ for the left ear in the same frequencies, respectively.

Authors such as Bonfils et al. ${ }^{14}$ (1993) and Abdala ${ }^{12}$ (1996) also found distortion product average amplitude responses in normal children with positive values in all the F2 frequencies tested.

As to the maximum response amplitude peaks, the literature shows values of $17.8 \mathrm{dBSPL}$ in $2 \mathrm{KHz}$, of $16 \mathrm{dBSPL}$ in $1.5 \mathrm{KHz} 12$, of $17.26 \mathrm{dBSPL}$ in $2 \mathrm{KHz}$, of 16.8 dBSPL in $1.5 \mathrm{KHz}$ and of $17.4 \mathrm{dBSPL}$ in $2 \mathrm{KHz}$. The results of the present investigation, in relation to the maximum distortion product amplitude response, are in agreement with those found in the literature; in other words, in the F2 frequency ranged around $2 \mathrm{KHz}$.

It was also seen that background noise average measures for both ears in the control group presented positive and high values in the lower frequencies and decreased as the frequencies become higher, taking on negative values starting in the frequency of $1187 \mathrm{~Hz}$ for the right ear and $1500 \mathrm{~Hz}$ for the left ear. The highest peak for negative values for background noise was seen in the frequencies of $3031 \mathrm{~Hz}$ and $3812 \mathrm{~Hz}$; with values of $-9.82 \mathrm{dBSPL}$ and $-9.73 \mathrm{dBSPL}$ for the right ear; and values of $-8.84 \mathrm{dBSPL}$ and -9.09 dBSPL for the left ear. 
Table 14 - mean values, standard deviation and t-student test (independent samples) in order to compare BN mean values between the control and study groups

\begin{tabular}{|c|c|c|c|c|c|c|}
\hline \multirow{2}{*}{$\mathrm{F} 2 \mathrm{~Hz}$} & \multicolumn{2}{|c|}{ Control } & \multicolumn{2}{|c|}{ Study } & \multirow{2}{*}{$p$-value ${ }^{1} \mathrm{~F}$} & \multirow{2}{*}{$\mathrm{p}$-value ${ }^{2} \mathrm{t}$} \\
\hline & Mean value $B N$ & Standard Deviation & Mean value $B N$ & Standard Deviation & & \\
\hline 593 & 9,7889 & 7,8146 & 8,3000 & 8,7499 & ,256 & ,258 \\
\hline 750 & 4,0111 & 7,2165 & 1,7000 & 7,5572 & ,490 & 051 \\
\hline 937 & 1,4778 & 5,1499 & ,3429 & 5,6309 & ,471 & , 186 \\
\hline 1187 & ,3000 & 5,3725 & $-2,3143$ & 5,2765 & ,892 &, $002\left(^{\star}\right)$ \\
\hline 1500 & $-2,5556$ & 5,5244 & $-3,0714$ & 5,3197 & ,414 &, 552 \\
\hline 1906 & $-5,0222$ & 4,1080 & $-5,2857$ & 4,4303 & ,981 & ,698 \\
\hline 2406 & $-7,8000$ & 3,2471 & $-7,9714$ & 3,2212 & ,837 & ,740 \\
\hline 3031 & $-9,3333$ & 3,9434 & $-9,7143$ & 3,6679 & ,858 &, 533 \\
\hline 3812 & $-9,4111$ & 3,1226 & $-9,2286$ & 3,1029 & ,839 &, 713 \\
\hline 4812 & $-8,4333$ & 2,4680 & $-8,4429$ & 2,6899 & ,751 & ,981 \\
\hline 6031 & $-7,4667$ & 2,1421 & $-7,7429$ & 2,7117 & ,034 & ,486 \\
\hline
\end{tabular}

Note: (1) Levene test for equality of variances, (2) t-Student test for independent samples. ${ }^{\star}$ ) Significant at $5 \%$

Results from the present investigation agree with those who found background noise taking on higher values in the lower frequencies. Bonfils et al. ${ }^{14}$ (1993) reported that the background noise had higher values in the lower frequencies and lower values in the higher frequencies. The same thing was noticed in the present study.

In regards to the difficulty in recording distortion product responses in the F2 frequencies, in the present investigation we observed that below the F2 frequency of $1500 \mathrm{~Hz}$, despite positive values for response average amplitudes, background noise was high and hampered response interpretation.

In relation to average amplitudes, given by the distortion product (signal) response amplitude difference with the background noise amplitude (table 7), it was observed that values equal to or above 6dBSPL were present starting in the F2 frequency equal to or higher than 1187 $\mathrm{Hz}$ for the right and left ears, showing maximum peaks in $1906 \mathrm{~Hz}$ and $2406 \mathrm{~Hz}$ with values of $21.36 \mathrm{dBSPL}$ and $22.67 \mathrm{dBSPL}$ for the right ear and in $2406 \mathrm{~Hz}$ and $3812 \mathrm{~Hz}$ with values of $21.89 \mathrm{dBSPL}$ and $19.07 \mathrm{dBSPL}$ for the left ear, respectively.

We may see that the best signal/noise difference amplitude averages are obtained in the frequency range of F2 where the best distortion product response amplitudes are present, coinciding with the lower values for background noise.

When we applied the t-Student (paired samples) test to compare the distortion product amplitude responses and those of the background noise for the right and left ears, we did not observe statistically significant differences ( $p$ $<0.05$ ) in any of the F2 frequencies tested.

In the present investigation, the distortion product amplitude averages for both, the right and left ears of the study group varied according to F2 frequency, presenting positive values in all tested frequencies of $1187 \mathrm{~Hz}, 1500$ $\mathrm{Hz}, 1906 \mathrm{~Hz}, 2406 \mathrm{~Hz}, 3031 \mathrm{~Hz}$ and $3812 \mathrm{~Hz}$ of the right ear and in the frequencies of $593 \mathrm{~Hz}, 1500 \mathrm{~Hz}, 1906 \mathrm{~Hz}$, $2406 \mathrm{~Hz}$ and $3812 \mathrm{~Hz}$ of the left ear. A maximum response amplitude peak was seen at $1906 \mathrm{~Hz}$ and $2406 \mathrm{~Hz}$ with values of $15.03 \mathrm{dBSPL}$ and $15.34 \mathrm{dBSPL}$ for the right ear, and values of $14.09 \mathrm{dBSPL}$ and $14.34 \mathrm{dBSPL}$ for the left ear, respectively.

By using the t-Student (paired samples) test in order to compare the distortion product amplitude response averages evaluated for the left and right ears of the study group, there was a statistically significant difference between the ears only in the F2 frequency of $1500 \mathrm{~Hz}$, and the right ear presented better response amplitude averages when compared to the left ear. As seen above, there are controversies in relation to the ear side that presents the best response amplitudes, in other words, authors said they found better response amplitudes for the right ears, while others observed response amplitude averages similar for both the right and left ears. In the present investigation, only one F2 frequency $(1500 \mathrm{~Hz}$ ) presented response amplitude averages that were better for the right ear when compared to the left ear in the study group.

We observed that the background noise measures for both the right and left ears of the study group presented positive values for the lower frequencies, with high values in the F2 frequency of $593 \mathrm{~Hz}$. It was also observed that the background noise decreased as the frequencies became higher, taking on negative values starting from F2 frequency of $1187 \mathrm{~Hz}$ for both ears (Table 9). Maximum peak of negative values for background noise occurred in 
the frequencies of $3031 \mathrm{~Hz}$ and $3812 \mathrm{~Hz}$, with values of $-10.23 \mathrm{dBSPL}$ and $-9.14 \mathrm{dBSPL}$, for the right ear, and with values of $-9.20 \mathrm{dBSPL}$ and $-9.31 \mathrm{dBSPL}$, for the left ear.

When we applied the t-Student (paired samples) test to compare background noises assessed for right and left ears, we did not find statistically significant differences between the ears, corroborating some aforementioned authors.

The amplitude averages of the signal/noise difference in the study group for the right and left ears presented values equal to or superior than $6 \mathrm{dBSPL}$ from the F2 frequency of $937 \mathrm{~Hz}$, showing maximum peaks of 20.60 dBSPL; $23.21 \mathrm{dBSPL}$ and $20.74 \mathrm{dBSPL}$ in the frequencies of $1906 \mathrm{~Hz}, 2406 \mathrm{~Hz}$ and $3031 \mathrm{~Hz}$, for the right ear; and of $19.66 \mathrm{dBSPL} ; 22.23 \mathrm{dBSPL}$ and $19.66 \mathrm{dBSPL}$ in the frequencies of $1906 \mathrm{~Hz}, 2406 \mathrm{~Hz}$ and $3812 \mathrm{~Hz}$, for the left ear, respectively (Table 10).

The best signal/noise ratio amplitude mean values were seen in the frequency range where the distortion product response amplitudes were broader and the background noise was lower.

When we compared the response amplitude mean values by the t-Student test (independent samples) in relation to gender for the control group, we observed a statistically significant difference $(\mathrm{p}>0.05)$ in two $\mathrm{F} 2$ frequencies only (1187 Hz and $1500 \mathrm{~Hz}$ ), and males had better average values (11.44 dBSPL and $14.46 \mathrm{dBSPL}$ ) when compared to females (8.44 dBSPL and 10.44 dBSPL).

In regards of background noise, the mean values did not present statistically significant differences between males and females compared to the control group.

For the study group response amplitude mean values (Table 13), the t-Student test (independent samples) for gender comparison, showed a statistically significant difference in one F2 frequency only $(2406 \mathrm{~Hz})$; when females presented a better mean value (16.28 dBSPL) when compared to males (13.28 dBSPL).

There was no statistically significant difference among background mean values between the genders (table 14), when the t-Student test was used (independent samples).

According to what was presented, we can notice that while males had better distortion product mean amplitude responses in two frequencies when compared to the control group, the same thing did not happen for the study group, in which women had better distortion product amplitude mean values in one frequency only.

We can see that exposure to occupational noise during pregnancy did not affect the hearing of children born from exposed mothers. The literature is scarce in studies about newborns' and infants' hearing, whose mothers were exposed to occupational noise during pregnancy. Lalande et al. ${ }^{27}$ (1986), in their study, stated that the proportion of children with significant hearing loss in $4 \mathrm{KHz}$ was 3 to 4 times greater when their mothers had been exposed to sound pressures of 85 to $95 \mathrm{dBSPL}$ in comparison to lower noise doses, and also that the lower frequencies are more affected.

Ando and Hattori ${ }^{23}$ (1970) reported on the greater skill the child had in adapting to the growing environmental noise when their mothers were exposed to noise during pregnancy, however they did not evaluate possible hearing loss. Gerhardt and Abrams ${ }^{21}$ (2000) reported hearing loss in the fetuses of mothers who were exposed to noise during pregnancy. However, in our study we did not notice hearing loss in fetuses from mothers exposed to occupational noise.

\section{CONCLUSION}

We did not notice a harmful effect on the hearing of children born from women exposed to occupational noise during pregnancy - evaluated by means of distortion product otoacoustic emissions, when compared to children born from women who were not exposed to occupational noise during pregnancy.

\section{REFERENCES}

1. Silveira JAM, Brandão ALA, De Rossi J, Ferreira LLA, Name MAM, Estefan P, Gonçalez F. Avaliação da alteração auditiva provocada pelo uso do walkman, por meio da audiometria tonal e das emissões otoacústicas (produtos de distorção): estudo de 40 orelhas. Rev Bras Otorrinolaringol 2001;65(5):650-4.

2. Martin GK, Ohlms LA, Franklin DJ, Harris FP, Lonsbury-Martin BL. Distortion product emissions in human. Influence of sensorineural hearing loss. Ann Otol Rhinol Laryngol Suppl 1990;147:30-42.

3. Probst R, Lonsbury-Martin BL, Martin GK, Coats AC. Otoacoustic emissions in ears with hearing loss. Am J Otolaryngol 1987;8:73-81.

4. Harris FP, Lonsbury-Martin BL, Stagner BB, Coats AC, Martin GK. Acoustic distortion products in humans: systematic changes in amplitudes as a function of f2/f1 ratio. J Acoust Soc Am 1989;85(1):2209.

5. Fukuda C, Munhoz MSL, Toledo FB, Hassan SE. Emissões otoacústicas por produto de distorção em trabalhadores expostos a ruído. Acta AWHO 1998;17(4):176-85.

6. Garcia AP, Snege YC, Azevedo MF, Soares E. Emissões otoacústicas evocadas transientes e emissões otoacústicas evocadas por produto de distorção em adultos normais: estudo dos desvios transitórios do limiar de audibilidade após exposição ao ruído. Pró-Fono Revista de Atualização Científica 1999;11(2):53-60.

7. Kimberley BP. Applications of distortion-product emissions to an otological practice. Laryngoscope 1999;109(12):1908-18.

8. Ferreira LLA, Silveira JAM, Percebo CC, Gonçalez F. Perda auditiva induzida por ruído: análise dos achados de audiometria tonal, potenciais evocados do tronco cerebral e emissões otoacústicas evocadas por produto de distorção. Rev Bras Otorrinolaringol 2001;67(1):9-14.

9. Gattaz G, Wazen SRG. O registro das emissões otoacústicas evocadas - produto de distorção em pacientes com perda auditiva induzida pelo ruído. Rev Bras Otorrinolaringol 2001;67(2):213-18.

10. Kemp DT, Ryan S. Otoacoustic emission tests in neonatal screening programmes. Acta Otolaryngol (Stockh) 1991;482:73-84.

11. Lopes Filho O, Carlos R, Redondo MC. Produtos de distorção das emissões otoacústicas. Rev Bras de Otorrinolaringol 1995;61(6):48594.

12. Abdala C. Distortion product otoacoustic emission (2f1-f2) amplitude 
as a function of $\mathrm{f} 2 / \mathrm{f} 1$ frequency ratio and primary tone level separation in human adults and neonates. J Acoust Soc Am 1996;100(6):372640.

13. Pelosi G, Hatzopoulos S, Chierici R, Vigi V, Martini A. Distortion product otoacoustic emission (DPOAEs) and newborn hearing screening: a feasibility and performance study. Acta Otorhinolaryngol Ital 2000;20(4):237-44.

14. Bonfils P, Avan P, François M, Loundon N, Elbez M, Tritoux J, Narcy $\mathrm{Ph}$. Dépistage de la surdité du jeune enfant - Intérêt, modalités techniques, résultats préliminaires des produits de distorsion acoustique. Ann Oto-Laryng (Paris) 1993;110:3-9.

15. Eckley CA, Duprat A, Lopes Filho O. Revisão: Emissões otoacústicas. Rev Bras Otorrinolaringol 1993;59(1):41-44

16. Mir Plana B, Sequi Canet JM, Paredes Cencillo C, Brines Solanes $\mathrm{J}$. Influence of the middle ear on the measurement of otoacoustic emissions. Rev Esp Pediatr 1997;47(2):162-6.

17. Pialarissi PR, Gattaz G. Emissões otoacústicas: conceitos básicos e aplicações clínicas. Arq Fund Otorrinolaringol 1997;1(2):36-39.

18. Pourbakht A, Sheykholeslami K, Kaga K. Distortion evoked otoacoustic emission using GSI 70 analyzer for neonatal screening. Int J Pediatr Otorhinolaryngol 2002;64(3):217-23.

19. Feinberg JS, Kelley CR. Pregnant workers. A physician's guide to assessing safe employment. West J Med 1998;168(2):86-92.

20. Gerhardt KJ, Abrams RM, Oliver CC. Sound environment of the fetal sheep. Am J Obstet Gynecol 1990;162(1):282-7.
21. Gerhardt KJ, Abrams RM. Fetal exposures to sound and vibroacoustic stimulation. J Perinatol 2000;20(8Pt2):21-30.

22. Niemtzow RC. Loud noise and pregnancy. Military Medicine 1993; 158:10-2.

23. Ando $\mathrm{Y}$, Hattori $\mathrm{H}$. Effects of intense noise during fetal life upon postnatal adaptability (statistical study of the reactions of babies to aircraft noise). J Am Acoust Soc 1970;47(4):1128-30.

24. Ando Y, Hattori H. Effects of noise on human placental lactogen (HPL) levels in maternal plasma. Br J Obstet Gynaecol 1977;84(2):115-8.

25. Zhang J, Cai WW, Lee DJ. Occupational hazards and pregnancy outcomes. Am J Ind Med 1992;21:397-408.

26. Murata M, Takigawa H, Sakamoto H. Teratogenic effects of noise and cadmium in mice: does noise have teratogenic potencial? J Toxicol Environ Health 1993;39(2):237-45.

27. Lalande NM, Hétu R, Lambert J. Is occupational noise exposure during pregnancy a risk factor of damage to the auditory system of the fetus? Am J Ind Med 1986;10(4):427-35.

28. Hartikainen AL, Sorri M, Anttonen H, Tuimala R, Läärä E. Effect of occupational noise on the course and outcome of pregnancy. Scand J Work Environ Health 1994;20(6):444-50.

29. Wu TN, Chen LJ, Lai JS, Ko GN, Shen CY, Chang PY. Prospective study of noise exposure during pregnancy on birth weight. Am J Epidemiol 1996;143(8):792-6.

30. Sobrian SK, Vaughn VT, Ashe WK, Markovic B, Djuric V, Jankovic BD. Gestational exposure to loud noise alters the development and postnatal responsiveness of humoral and cellular components of the immune system in offspring. Environ Res 1997;73(1-2):227-41. 